\title{
Effectiveness of screening for congenital dislocation of the hip
}

\author{
E G KNOX, E H ARMSTRONG, AND R J LANCASHIRE \\ From the Department of Social Medicine, University of Birmingham, Medical School, Edgbaston, Birmingham \\ B15 2TJ
}

SUMMARY The incidence of congenital dislocation of the hip (CDH) in Birmingham was measured in the period 1942-52 and again in 1950-54; it is measured now in 1974-83. Despite the introduction of neonatal screening for CDH in November 1966, between the times of the earlier and the present measurements there was no indication that $\mathrm{CDH}$ requiring prolonged treatment had declined. The performance of the procedure itself was poor. It detected only a third of genuine cases, and the false positives outnumbered the true positives by 10:1. The incidence of 'definite' cases varied markedly from year to year in a manner suggesting diagnostic idiosyncracies rather than genuine fluctuations. There was no evidence in particular maternity units that high levels of early detection led to low levels of late diagnosis. Indeed, maternity units with the worst results - the highest rates of late diagnosis and of prolonged treatment-had the highest rates of early detection and early treatment. Current theories of natural history, aetiology, and treatment should be reappraised.

In the period $1942-52$, before the introduction of neonatal screening, the incidence of treated congenital dislocation of the hip (CDH) in Birmingham was 0.65 per 1000 births. $^{1}$ In the partly overlapping period 1950-54, it was 0.91 per 1000 births. $^{2}$ The second investigation used a wider range of data sources. Very few infants were diagnosed in the neonatal period: about 0.03 per thousand births. A major effort was subsequently made in Birmingham, from November 1966 , to screen all newborns. ${ }^{3}$ It was hoped that early detection would greatly reduce the incidence of delayed diagnosis, limit the need for surgery and prolonged treatment, and reduce the prevalence of disability.

Department of Health and Social Security (DHSS) guidelines on clinical techniques were published in $1969^{4}$ and in $1986,{ }^{5}$ but little thought was given in 1966 to the quality control of the programme as a whole, and no provision was made to measure its effectiveness in terms of a reduced incidence of late diagnosed $\mathrm{CDH}$. Notification of congenital malformations to the Office of Population Census and Surveys (OPCS) on a nationwide scale began in 1964, and CDH had become a notifiable condition. Numbers of neonatal detections could thus be recorded, but limitation of the notification scheme to malformations recognised in the first 7 days of life meant that it could not monitor national or local reductions in the frequency of late presentations, the essential criterion of success.
From 1976 onwards reports began to appear which cast serious doubts upon the effectiveness of $\mathrm{CDH}$ programmes. ${ }^{6-13}$ They showed little evidence of substantial reductions of late presenting $\mathrm{CDH}$ and, in some cases, an increase. In some investigations it was suggested that the screening procedure itself, or perhaps early treatment of unstable hips, might have caused a dislocation to become established.

Our purpose in this report is to examine the problem in Birmingham using the facilities of the Birmingham Birth Register and the Birmingham Malformations Register.

\section{Materials and methods}

The Birmingham Birth Register (BBR) and Birmingham Malformations Register (BMR) maintain summaried records of all Birmingham births and all congenital malformations. The initial ascertainment of malformations is based upon birth notifications, maternity reports, and notifications of malformations to OPCS. These initial reports are later supplemented by health visitor records and by Hospital Activity Analysis (HAA) searches for admissions of children up to 5 years of age where there was mention of a malformation. Ascertainment of malformations evident before 5 years of age is essentially complete except for children who may have left the city and a small number of late "inward 
transfers" of Birmingham residents delivered elsewhere. $^{14}$

Detailed classification of the malformations relies upon the reported diagnoses of clinicians in charge, supplemented in fatal cases by necropsy reports and in subsequently treated cases by HAA diagnostic codings. For "doubtful" diagnoses (including talipes, heart murmurs, clicking hips, and "generic malformations otherwise unspecified"), and for those which lacked a subsequent consistent confirmation, we examined clinical records directly. For $\mathrm{CDH}$ we examined the original neonatal and HAA-listed hospital records for all disorders of the hip up to the age of 5 years among children born to Birmingham residents between 1974 and 1983 . We also searched diagnostic indexes of outpatient clinics of children's hospitals, paediatric and orthopaedic units, and neonatal follow-up clinics of maternity units and, where hip disorders were indexed, the clinical notes were examined. Substantial periods of treatment or surveillance would certainly have been recorded by the health visitor even if a child had not been admitted to hospital, but shorter episodes might have escaped our notice. With this additional material, the only cases we were likely to 'miss' or 'misclassify' were (a) those who moved out of the city before diagnosis, and (b) infants referred to outpatient clinics or neonatal follow-up clinics where no diagnostic index was kept and where the child was discharged from care without ever being admitted to hospital.

The poor organisation of outpatient record systems, and a general absence of diagnostic indexes, partly frustrated these additional searches. Only two maternity units and none of the orthopaedic outpatient clinics had follow-up clinics with a consistently maintained diagnostic index. Enquiries at plaster rooms and at $x$-ray departments proved to be fruitless. In the event, the two "indexed" neonatal clinics recorded transient instabilities of the hip in numbers sufficient to suggest the untraced attendance of similar children at other units. In-patient record systems were well kept. All HAA-indexed records were eventually traced and inspected.

These extended searches failed to reveal any undoubtedly genuine dislocations of which we had been unaware. The additional ascertainments came entirely from the indexed neonatal clinics and consisted entirely of infants receiving no treatment or short and tentative treatments or whose referrals for an additional opinion led to neither a substantive diagnosis nor additional treatment.

\section{Results}

INCIDENCE

From 1974 through 1983 there were 144246 total births to Birmingham residents (excluding residents of Sutton Coldfield) in the area covered by BMR and BBR. During this time BMR identified 557 children in whom $\mathrm{CDH}$ was at some time diagnosed. This amounts to 3.86 per thousand births. Of these 557,314 had a "notification code"; that is, they were notified to OPCS through the national Congenital Malformations Notification Scheme. On this basis, the incidence would appear as 2.17 per 1000 total births.

Other infants were reported to OPCS and/or to BMR with a "clicking" hip. OPCS classifies them under a rubric separate from $\mathrm{CDH}$, and they were not accepted as "valid" malformations within BMR. They are therefore excluded from both measures of incidence. It was possible subsequently to link late presenting cases of $\mathrm{CDH}$ with neonatal reports to see how many of them were in fact preceded by that condition; none was.

In order to compare the current incidence of $\mathrm{CDH}$ with the estimates of 1942-52 and 1950-54 we must identify comparable cases. Among the 557 children reported to have $\mathrm{CDH}, 83$ had surgery or prolonged splinting of 16 weeks or more, and another 13 had shorter periods of treatment beginning at 18 weeks of age or later. These 96 cases probably represent the closest approach we can achieve to the definition used in the earlier studies, and this gives an incidence of 0.67 per 1000 total births, almost exactly the same as in 1942-52 (0.65) but somewhat less than the more reliable estimate of 1950-54 (0.91).

There have been major demographic changes in Birmingham since the earlier measures of incidence were made. In the period $1974-83,69 \%$ of babies were to Caucasian mothers compared with the almost total predominance of Caucasian births in 1950. Ninetythree of the 96 cases mentioned above were born to Caucasians, giving an incidence of 0.93 per thousand. There is no evidence of a substantial change.

Sixty-four of the 96 cases in 1974-83 (67\%) were first treated after the age of 18 weeks and seemed quite clearly to have slipped through the screen; either they were "missed" or they developed late.

\section{SENSITIVITY AND SPECIFICITY}

In order to estimate these parameters we must try to distinguish (a) infants diagnosed and treated early, for whom a later disability was otherwise inevitable (the true positives), (b) those whose dislocations were missed or not yet present and who were diagnosed and treated later (the false negatives), and (c) children diagnosed unjustifiably in that they needed no treatment at all (the false positives).

There is no objective criterion for distinguishing "true" from "false" positives, and the best available guide is probably a record of a specialist orthopaedic 
assessment and a note of the action taken. It is for this last reason that we include an operational as well as a diagnostic element in our definition of a true positive (above). A "medical behavioural" definition to some extent begs the questions in hand, but we can add to the precision of the analysis by classifying the children according to the ages at which they were first treated, and the duration and extent of the treatment given. This emphasis on the timing and duration of treatment was to some extent enforced by the inadequacies of the medical records that we inspected. The treatments were more often and more consistently dated than were the diagnoses. A two-way distribution in those terms is presented in table 1 .

Table 1 identifies the 83 children who had surgery or prolonged splinting (mentioned earlier) and the 13 $(4+3+5+1)$ who had less prolonged treatment of late onset. These are the 96 cases used for comparison with the earlier periods. The 32 who began a prolonged spell of treatment starting within 18 weeks were regarded as true positives on neonatal screening, and the 64 who began late $(15+36+13)$ were regarded as false negatives. The 18-week dividing line was chosen partly because it was the antimode of the distribution; partly because it seemed likely that if no record of starting or modifying a substantive treatment had been made at this age then none had been given; and partly because increasing infant mobility beyond this age would suggest that later diagnoses had been reached on the grounds of visible impairments rather than through screening.

Table 1 also indentifies 114 children who were not treated at all and suffered no subsequent harm, and another 114 who had short early periods of treatment, many for two or three weeks only. All 228 children can reasonably be regarded as "false positives" on initial assessment. Another 37, first splinted in the neonatal period, had no record of referral or of duration. Another 121 could not readily be located within the body of the table; 23 were referred to orthopaedic clinics, but the notes, when traced, did not mention $\mathrm{CDH}$ at all, while in another 23 referred cases no notes were found. Eight children had died in the neonatal period and 18 had additional malformations to which the dislocation was perhaps secondary. The remaining children in this group had a note of intended referral in the neonatal notes but without evidence that an appointment had been made or that the child had been seen. We suspect that many were seen the same day, informally, without a separate appointment being made or recorded. Except for the eight deaths and the 18 multiple malformations, this group of 121 must be regarded in the main as false positives.

Another 75 children were splinted for periods of 9 to 16 weeks beginning before 18 weeks of age. It is impossible to say exactly what proportion should be regarded as true positives and scored as screening "successes", and what proportions should be regarded as false positives. However, any substantial number of true positives would raise current estimates of total incidence well above those for 1950-54. In addition, table 1 shows that the "sensitivity" of neonatal screening - as judged by the proportion treated before 18 weeks - seems to increase as the assessed severity of the condition (duration of treatment) decreases. We would expect the more severe instabilities to be most readily detectable within the neonatal period. We infer that the majority of these positives were false, although not necessarily all of them.

Precise estimates of the sensitivity and false-positive rates of neonatal screening cannot be made, but estimates using different definitions are given in

Table 1 Timing, type, and duration of treatment of $C D H$

Duration of splinting (weeks)

\begin{tabular}{|c|c|c|c|c|c|c|}
\hline $\begin{array}{l}\text { Age first } \\
\text { treated }\end{array}$ & $>17^{*}$ & 916 & $<<8$ & None & $\begin{array}{l}\text { Duration not } \\
\text { recorded }\end{array}$ & Total \\
\hline No treatment & - & - & - & $114(42) \dagger$ & - & $114(42)$ \\
\hline $\begin{array}{l}\text { Early: } \\
\text { before } 18 \text { weeks }\end{array}$ & $32(21)$ & $75(51)$ & $114(87)$ & - & 37 (19) & $258(178)$ \\
\hline Intermediate & $15(1)$ & $4(1)$ & $3(1)$ & - & - & $22 \quad(3)$ \\
\hline $\begin{array}{l}\text { No documentation/ } \\
\text { wrong diagnosis/ } \\
\text { dead/misclassified; } \\
\text { multiple/secondary ... etc }\end{array}$ & - & - & - & - & $121(88)$ & $121(88)$ \\
\hline Total & $83(24)$ & $84(52)$ & $118(89)$ & $114(42)$ & $158(107)$ & $557(314)$ \\
\hline
\end{tabular}

* Includes 57 children who had surgery in addition to splinting, and 3 who had surgery alone with no separately recorded splinting.

$\dagger$ Figures in parenthesis indicate those children who were known to OPCS through the notification scheme. Most of them were probably recorded as CDH alone. but some (especially those with intermediate or late treatments) were notified as "multiple malformations" or as other malformations to which CDH was secondary. 
Table 2 Incidence of " $C D H$ " based on alternative definitions

\begin{tabular}{|c|c|c|c|c|}
\hline \multicolumn{2}{|c|}{ Definition of $C D H$} & \multirow{2}{*}{$\begin{array}{l}n \\
557\end{array}$} & \multirow{2}{*}{$\begin{array}{l}\text { Incidence }\left(10^{-3}\right) \\
3.86\end{array}$} & \multirow{2}{*}{$\begin{array}{l}\begin{array}{l}\text { False } \\
\text { positives } \\
\%^{*}\end{array} \\
83\end{array}$} \\
\hline (a) & All cases traced & & & \\
\hline (b) & $\begin{array}{l}\text { Excluding secondary } \mathrm{CDH} \text {, } \\
\text { neonatal deaths, and cases } \\
\text { without recorded treatment or referral }\end{array}$ & 322 & $2 \cdot 23$ & 70 \\
\hline (c) & $\begin{array}{l}\text { Further exclusion of short or } \\
\text { unrecorded splinting of early onset }\end{array}$ & 171 & $1 \cdot 19$ & 44 \\
\hline (d) & $\begin{array}{l}\text { Surgery or prolonged treatment; } \\
\text { or any splinting beginning after } 18 \text { weeks }\end{array}$ & 96 & 0.67 & 0 \\
\hline (e) & Late treated $\mathrm{CDH}$ ( $>18$ weeks of age) & 64 & 0.44 & - \\
\hline (f) & $\begin{array}{l}\text { Previously measured incidence } \\
\text { (1942-52) of all treated cases }\end{array}$ & 148 & 0.65 & - \\
\hline
\end{tabular}

\footnotetext{
*We suppose group (d) to represent the "genuine" cases of $\mathrm{CDH}$, then: Sensitivity $[(\mathrm{d}-\mathrm{e}) / \mathrm{d}]=33 \%$

Specificity $(144246-a) /(144246-d)=99.68 \%$

Percentage of false positives for $(a)=[(a-d) / a]=83 \% \ldots$ and similarly for subsequent rows of the final column
}

table 2 . Over $80 \%$ of all the diagnosis reported to us were probably false positives. The sensitivity of the procedure was about $33 \%$. If some of the early "positives" were "true" rather than "false", then it might be a little higher but probably not beyond $50 \%$. Approximately $28 \%$ of "genuine" cases were known to OPCS, whether under the rubric $\mathrm{CDH}$ or some other rubric (another malformation), and about $90 \%$ of OPCS-notified cases were false positives.

TIME AND PLACE

Table 3 gives the distribution of the different subgroups in successive years. The "definite" cases in this table correspond with group (d) of table 2; they showed wide variations with 22 and 17 such cases in the worst years and 3 and 2 in the best. Styles of treatment also changed.
These diagnostic idiosyncracies are illustrated again in table 4 where the incidence varies widely between the different maternity units. The diagnostic classes are regrouped here to reflect as nearly as possible the successes and failures of neonatal screening. The first column represents the substantive failures of the screening service, dislocations that were both late treated and severe $(36+15$, from table 1). The 190 infants in the third column are false positives. The central column is intermediate; the majority (see earlier) are probably false positives. but it alse contains genuine cases who received early (although? extended) treatment, and may contain others where early treatment of intermediate duration averted prolonged splinting. Part of the variation between maternity units in the last two columns reflects the existence of indexing systems in hospitals $\mathrm{A}$ and $\mathrm{F}$,

Table 3 Year of birth by diagnostic subgroup

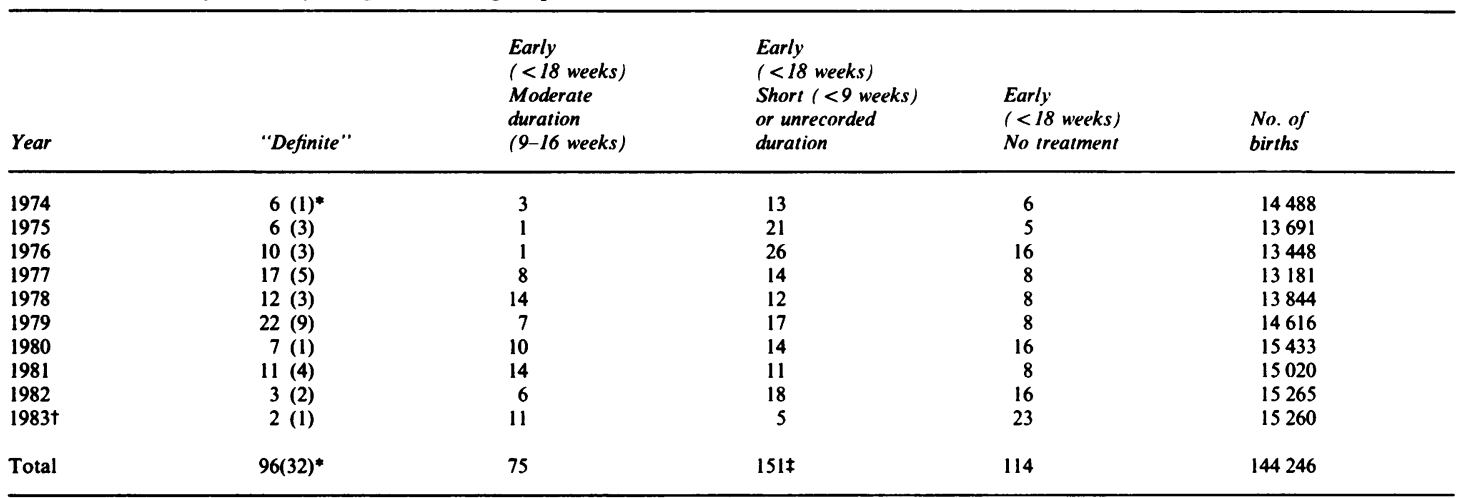

- Figures in parentheses are of children treated in first 8 weeks of life

$\dagger$ Ascertainment of late presentations among 1983 births may still be incomplete in 1986

¥ 114 from column 3 of table 1 plus 37 from column 5 
Table 4 Screening class by maternity unit: numbers $(n)$ and incidence (i), all ethnic groups

\begin{tabular}{|c|c|c|c|c|c|c|c|}
\hline \multirow[b]{3}{*}{ Unit } & \multirow[b]{3}{*}{ No. of births } & \multicolumn{6}{|c|}{ Treatment class } \\
\hline & & \multicolumn{2}{|c|}{$\begin{array}{l}\text { Late, severe* } \\
\text { (ie, "missed") }\end{array}$} & \multicolumn{2}{|c|}{$\begin{array}{l}\text { Early, moderatet } \\
\text { to severe }\end{array}$} & \multicolumn{2}{|c|}{$\begin{array}{l}\text { Early, temporaryt } \\
\text { or nil }\end{array}$} \\
\hline & & $n$ & $i\left(10^{-3}\right)$ & $n$ & $i\left(10^{-3}\right)$ & $n$ & $i\left(10^{-3}\right)$ \\
\hline $\begin{array}{l}\text { A } \\
\text { B } \\
\text { C } \\
\text { D } \\
\text { E } \\
\text { F } \\
\text { G } \\
\text { Other }\end{array}$ & $\begin{array}{r}32956 \\
27153 \\
20939 \\
9068 \\
19979 \\
11657 \\
16980 \\
5514\end{array}$ & $\begin{array}{r}12 \\
6 \\
11 \\
2 \\
2 \\
11 \\
4 \\
3\end{array}$ & $\begin{array}{l}0.36 \\
0.22 \\
0.53 \\
0.22 \\
0.10 \\
0.94 \\
0.23 \\
0.54\end{array}$ & $\begin{array}{r}24 \\
3 \\
5 \\
2 \\
3 \\
59 \\
11 \\
0\end{array}$ & $\begin{array}{l}0.73 \\
0.11 \\
0.24 \\
0.22 \\
0.15 \\
5.06 \\
0.65 \\
-\end{array}$ & $\begin{array}{r}133 \\
4 \\
3 \\
2 \\
11 \\
33 \\
8 \\
2\end{array}$ & $\begin{array}{l}4.04 \\
0.15 \\
0.14 \\
0.22 \\
0.55 \\
2.83 \\
0.47 \\
0.36\end{array}$ \\
\hline $\begin{array}{l}\text { Total } \\
\text { A,C,F, } \\
\text { B,D,E,G }\end{array}$ & $\begin{array}{r}144246 \\
65552 \\
73180\end{array}$ & $\begin{array}{l}51 \\
34 \\
14\end{array}$ & $\begin{array}{l}0.35 \\
0.52 \\
0.19\end{array}$ & $\begin{array}{r}107 \\
88 \\
19\end{array}$ & $\begin{array}{l}0.74 \\
1.34 \\
0.26\end{array}$ & $\begin{array}{r}196 \\
169 \\
25\end{array}$ & $\begin{array}{l}1 \cdot 36 \\
2 \cdot 58 \\
0 \cdot 34\end{array}$ \\
\hline
\end{tabular}

through which many of the false positives were traced. They result in a relative "inflation" of some of the figures.

It might be supposed that those units which exhibit the lowest rates of missed late presenting cases might be those which detected and treated the greatest number of hip instabilities in the early weeks. The data were therefore aggregated as nearly as possible into two equal groups, the first consisting of hospitals with the highest rates of severe $\mathrm{CDH}$, the second group with the lowest rates. These aggregated results are given at the foot of table 4. The three "worst" (A,C,F, ) hospitals displayed a combined incidence of 0.52 "missed" cases per 1000 births while the four best had an incidence of $0 \cdot 19$ per 1000 .

Paradoxically, the hospitals with the 3 worst results displayed the highest rates of early detection and early treatment. High awareness, high early detection rates, high early treatment rates, and prolonged early treatments were followed by a high incidence rather than a low incidence of late recognised dislocations requiring prolonged splinting or surgery.

This might have been explained by the reputed low incidence of $\mathrm{CDH}$ among immigrants and a concentration of births to immigrant families in particular hospitals. The data of table 4 were therefore re-assembled for Caucasian births alone (British, Irish, and other European), and the results are given in table 5. The three hospitals with the highest rates of late diagnosed $\mathrm{CDH}$ among all births (in table 4) had the three highest among Caucasians. The positive relation between high levels of early and late diagnosis was confirmed. The ethnic hypothesis is not the true explanation, although it is confirmed that the incidence is greater among Caucasians than among Asian and Afro-Caribbean immigrants.

ONE DISEASE OR TWO?

An alternative (partial) explanation of the concordant rates for early and late $\mathrm{CDH}$ could be the coexistence of two different diseases with different aetiologies. Hypothetically, the first occurs early and is transient while the second is either early or late and requires prolonged treatment. Better screening detects both of them in larger numbers.

Table 6 tests the two-disease hypothesis by comparing the 83 cases of $\mathrm{CDH}$ which required either surgery or prolonged splinting (column 1 of table 1) with all other cases. Since almost all cases of $\mathrm{CDH}$ occurred in Caucasians, the table provides similar figures for the whole Caucasian population of Birmingham. We found that the two "grades" of CDH differed jointly in several respects from the population at large, but they did not differ substantially from each other. They appear to be elements of a continuum.

The well recognised excess of breech presentations was evident in both sets; there was also an excess of caesarean deliveries. An excess of maternal $x$ rays during pregnancy, again evident in both sets, once more reflects a raised frequency of pregnancy problems. An excess of female children was evident in both groups. The seasonal variation detected in the 1942-52 study-an excess from October to Marchwas not confirmed. The greatest frequency was between July and December.

The question of heterogeneity was pursued further in a study of laterality, and this interacted with mode of delivery. The ratio of unilateral to bilateral CDH 
Table 5 Screening class by maternity unit: numbers ( $n$ ) and incidence (i), Caucasian mothers only (British, Irish plus other European)

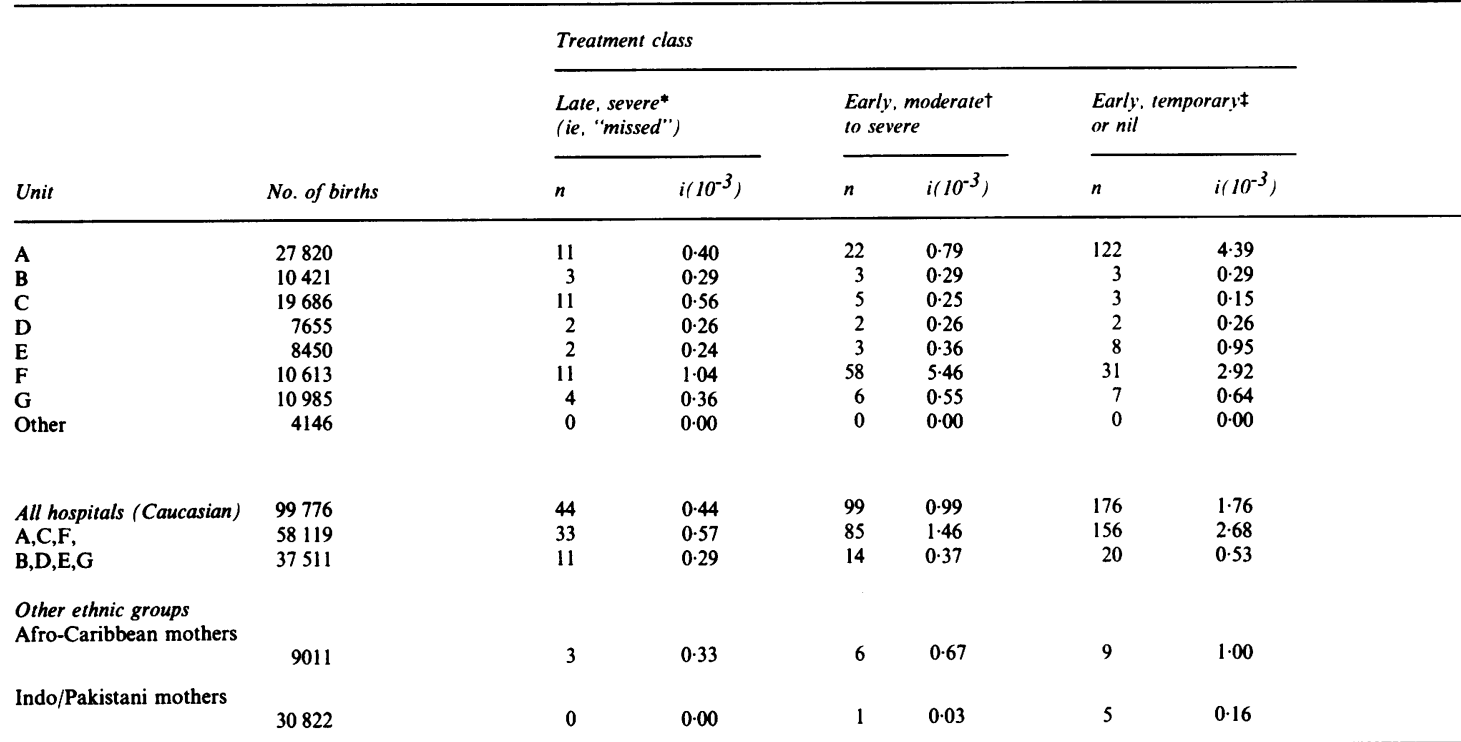

* Operation, or splinting of $17+$ weeks: first treatment after 18 weeks of age $(15+36$ of table 1$)$

+ Splinted for 9 weeks or more: first treatment before 18 weeks $(75+32$ of tablel $)$

Splinted for less than 8 weeks, or undergoing a period of surveillance with diagnosis before 18 weeks $(114+114$ of table 1 , less 32 untreated cases where consultants specifically excluded CDH and discharged the patient immediately without further follow up)

Table 6 Social and obstetric differences between treatment groups

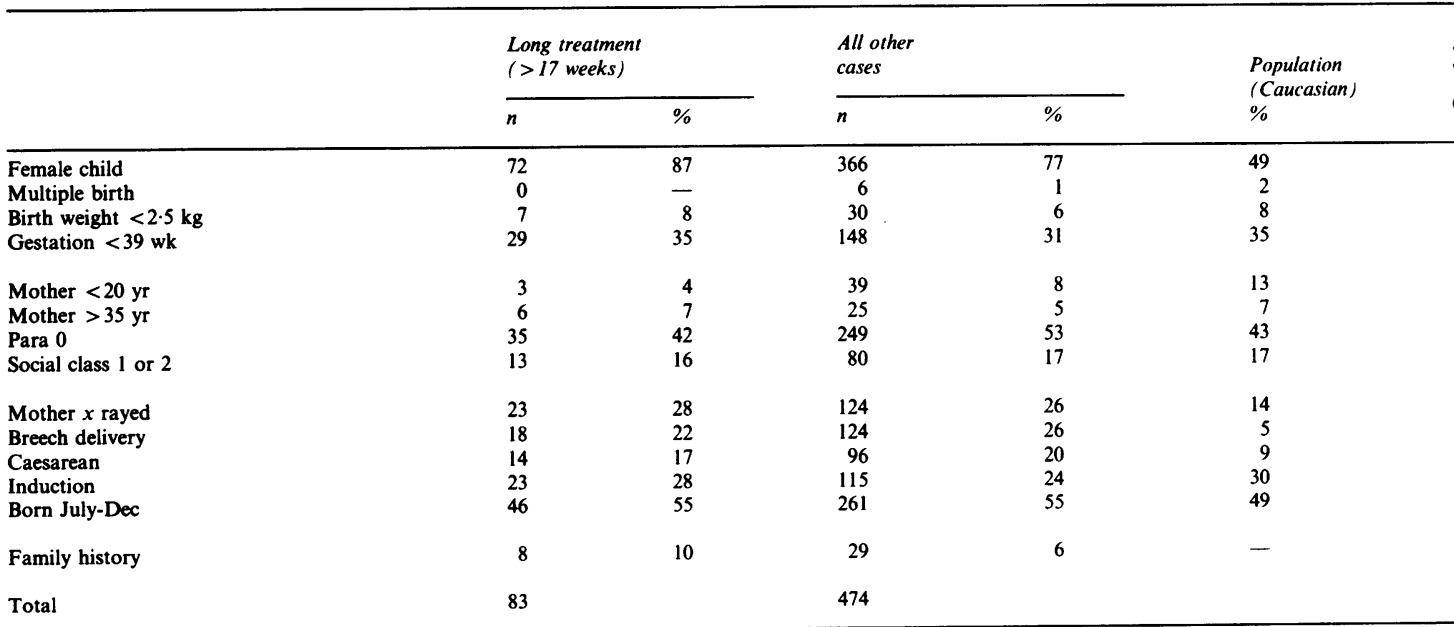

was $2 \cdot 22$ among infants with a vertex delivery but only 0.84 among those with breech vaginal deliveries or caesarean sections. The pattern was common to the two subclasses of $\mathrm{CDH}$, and there was no distinction between them in this respect.

\section{Discussion}

(1) The incidence of $\mathrm{CDH}$ requiring prolonged treatment was no less in the Caucasian population in the period 1974-83 than it was before widespread neonatal screening was introduced.

(2) Late diagnosis was the rule rather than the exception, and the sensitivity of the procedure in the neonatal period was about $33 \%$. Among "detections" under the age of 18 weeks the false positives outnumbered the true positives by about 10:1. The distinction between false positives and true positives 
was not always clear, but it would not be possible to suppose that many more of the positives were "true" without supposing that the incidence had risen substantially.

(3) Cases needing major treatment following a late diagnosis were more frequent in those maternity units which had high rates of early diagnosis. It has been suggested elsewhere that the test itself may be a cause of CDH; or perhaps the enthusiastic pursuit of early detection results in a number of unjustifiable diagnoses and unnecessary prolonged treatments. Early treatment might itself supposedly consolidate rather than avert the persistence of an early instability.

There was no evidence from the data that these paradoxical associations could be explained through concentrations of births to immigrant women in particular units, and there is no evidence that we are dealing with more than one condition. $\mathrm{CDH}$ appears to be part of a continuum extending from mild to major instabilities.

(4) Part of the aetiology must lie in the antenatal period and in the birth process, as evidenced by the increased incidence among both breech and caesarean deliveries and in the children of mothers who were $x$ rayed.

There must also be a postnatal element, and the total absence of severe or late instabilities in infants born to women from the Indian subcontinent is striking. It is certainly not due to back-carriage and maintenance of the "frog" position in the infant, the explanation sometimes offered for the reputed low incidence in African populations. It is also noteworthy that three genuine cases occurred among children of Birmingham Afro-Carribean mothers, a group with a longer period of western acculturation than the Asian population.

(5) The service failures recorded here are no doubt due partly to lack of proper organisation, lack of quality control, lack of monitoring, and lack of feedback to those responsible for clinical procedures. There is no clear assignment of responsibilities for these functions or indeed for the performance of the service. However, the failures seemed to be especially associated with hospitals where the clinical service was well organised, and their causes might therefore be of a more fundamental nature.

(6) These results suggest that the natural history, the age at onset, and the nature of the postpartum determinants of dislocated hip have been misunderstood. Theories and treatments based upon the hypothesis that the persistence of an instability is determined by posture might not be correct. The persistence of an initial instability might be less a function of the position in which the hip is held (extension/flexion) and more a function of immobility of any kind as opposed to unrestrained mobility. Work from Japan, where the incidence is high, could be interpreted in this way. ${ }^{15}$ A detailed study of infant handling techniques by Asian mothers could pay dividends.

This work was carried out as part of a Health Services Research Programme supported by DHSS and by the West Midlands Regional Health Authority.

\section{References}

${ }^{1}$ Record RG, Edwards JH. Environmental influences related to the aetiology of congenital dislocation of the hip. Br J Prev Soc Med 1958; 12: 8-22.

${ }^{2}$ Leck I, Record RG, McKeown T, Edwards JH. The incidence of malformations in Birmingham, England, 1950-1959. Teratology 1968; 1: 263-80.

${ }^{3}$ City of Birmingham Report of the Medical Officer of Health for the year 1967, 115 .

${ }^{4}$ DHSS. Screening for the detection of congenital dislocation of the hip in infants. Prepared by the Standing Medical Advisory Committee for the Central Health Services Council and the Secretary of State for Social Services, 1969.

${ }^{5}$ DHSS. Screening for the detection of congenital dislocation of the hip. Prepared by the Standing Medical Advisory Committee and the Standing Nursing and Midwifery Advisory Committee for the Secretaries of State for Social Services and for Wales, 1986.

${ }^{6}$ Klingberg MA, Chen R, Chemke J, Levin S. Rising rates of congenital dislocation of the hip (Letter to the Editor) Lancet 1976; i: 298.

${ }^{7}$ Place MJ, Parkin DM, Fitton JM. (1978) Effectiveness of neonatal screening for congentital dislocation of the hip. Lancet ii: 249-51.

${ }^{8}$ Catford JC, Bennet GC, Wilkinson JA. Congenital hip dislocation: an increasing and still uncontrolled disability? Br Med J 1982; 285: 1527-30.

${ }^{9}$ Leck I. An epidemiological assessment of neonatal screening for dislocation of the hip. J Roy Coll Phys 1986; 20: $56-62$.

${ }^{10}$ Anon. Epiphysitis in congenital dislocation of the hip. $\mathrm{Br}$ Med J 1981; 282: 926.

11 David TJ, et al. Reasons for late detection of hip dislocation in childhood. Lancet 1983; ii: 147-8.

12 Roberton NRC. Screening for congenital hip dislocation. Lancet 1984; i: 909-10.

${ }^{13}$ Rao S, Thurston AJ. Congenital dislocation of the hip in the newborn: a postnatal survey. New Z Med J 1986; 752-54.

${ }^{14}$ Knox EG, Armstrong EH, Lancashire R. The quality of notification of congenital malformations. $J$ Epidemiol Community Health 1984; 38: 296-305.

${ }^{15}$ Yamamuro T, Ishida K. Recent advances in the prevention, early diagnosis, and treatment of congenital dislocation of the hip in Japan. Clin Orthop 1984; 184: 34-40. 